\title{
Recrystallization of Tantalum
}

\author{
by G. W. Wensch, K. B. Bruckart, and R. H. Deibler
}

$\mathbf{P}$ RIMARY recrystallization kinetics of high purity tantalum (99.9 pct), which had been reduced 40 pct in thickness by cold rolling, were studied and the kinetic relations determined. Tantalum strips, $6 \times 0.5 \times 0.075$ in., were isothermally annealed in a vacuum at 0.5 micron $\mathrm{Hg}$ with the strips as the heating elements. Temperature gradients throughout the specimen length were largely eliminated by decreasing the cross-sectional area of the specimens at the cold electrode clamps.

Temperature sightings were taken normal to the flat surface of the specimens at midcenter, using a Leeds \& Northrup optical pyrometer. Sighting was through a glass window of approximately 95 pct transmission, and black body temperature corrections were made using published emissivity values.

Each specimen was annealed at constant temperature by controlling the energy input so the brightness of the specimen remained constant by comparison with a predetermined setting of the optical pyrometer. Time at temperature was measured to 0.1 min with a stop watch. Heating times to the annealing temperatures were short as a modified pulse annealing procedure was used. ${ }^{2}$ A larger current was used initially to bring the specimen to temperature after which a lower current was used to maintain the annealing temperature. Recrystallization effects occurring during the cooling cycle appear negligible as determined by the method of kinetic analysis of Parkins, Dienes, and Brown. ${ }^{2}$

The approximate times necessary for complete recrystallization were found by microscopic examination of representative electropolished ${ }^{3}$ and etched surfaces. After a time bracket was established roughly for each temperature, additional specimens were annealed at a specific temperature using a reiteration change in annealing time until a reasonably accurate time bracket was established.

Table I. Time-Temperature Data for the Recrystallization of 40 Pct Cold Rolled Tantalum*

\begin{tabular}{ccl}
\hline $\begin{array}{c}\text { Annealing } \\
\text { Temperature, } \\
\text { oK }\end{array}$ & $\begin{array}{c}\text { Annealing } \\
\text { Time, } \\
\text { Min }\end{array}$ & \multicolumn{1}{c}{$\begin{array}{c}\text { State of } \\
\text { Tantalum* }\end{array}$} \\
\hline 1520 & 110.00 & Partial recrystallization \\
1520 & 140.0 & Full recrystallization \\
1570 & 30.0 & Partial recrystallization \\
1570 & 35.0 & Full recrystallization \\
1620 & 12.0 & Partial recrystallization \\
1620 & 14.0 & Full recrystallization \\
1670 & 3.0 & Partial recrystallization \\
1670 & 3.5 & Full recrystallization \\
Penultimate & grain & size $0.030 \mathrm{~mm}$ diam. \\
\hline
\end{tabular}

The recrystallization state of the specimens, which were used in finally placing the end point of recrystallization, was determined by X-ray back reflection patterns. Copper $\mathrm{K}$-alpha radiation was used to examine the 321 family of planes. The presence of the resolved doublet was used as the criterion for the existence of unrecrystallized material. The intensity integration of the 48 contribut-

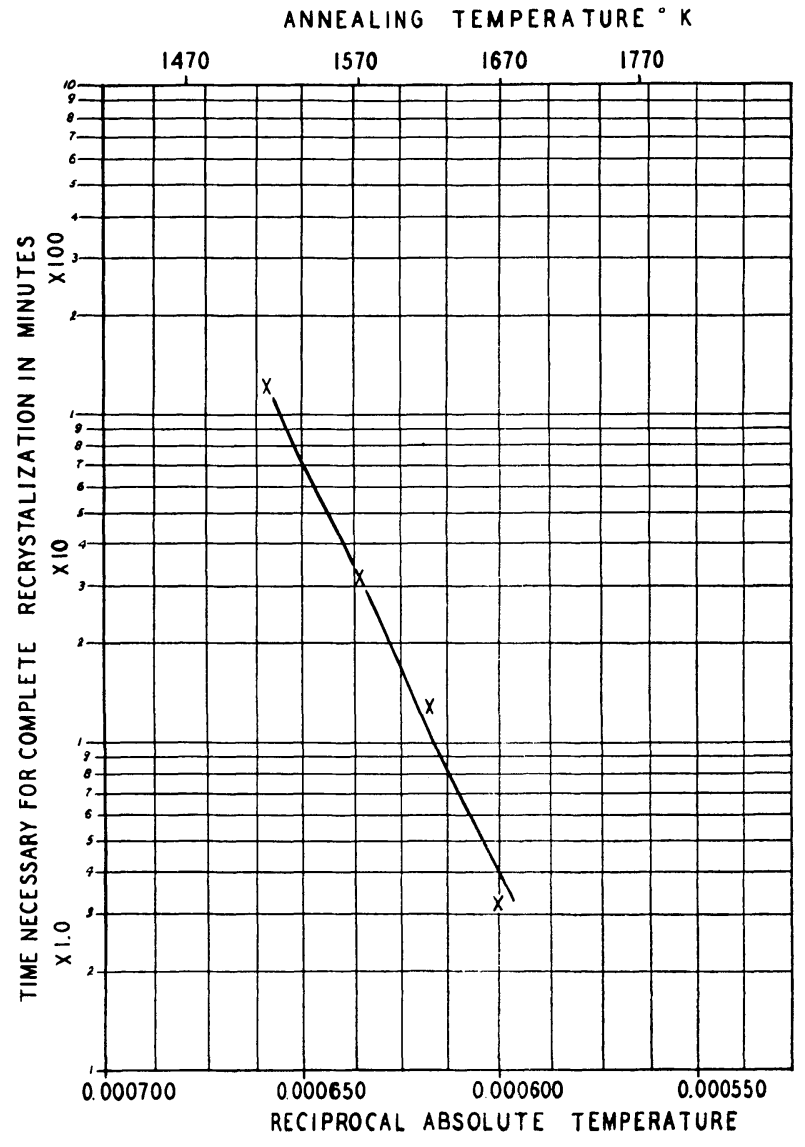

Fig. 1-Plot of time-temperature data given in Table I for the recrystallization of 40 pct cold rolled tantalum.

ing planes of this (hkl) family permitted a thorough statistical survey of the recrystallization state of the tantalum lattice.

Experimental data are given in Table $I$ and plotted in Fig. 1. The heat of activation for recrystallization was found to be $124 \pm 4 \mathrm{kcal}$ per molconsiderably higher than the values reported for other metals.

\section{Acknowledgment}

The authors express their gratitude for the assistance given by Dr. L. F. Yntema, director of research, and R. W. Yancey, chief metallurgist of the Fansteel Metallurgical Corp.

\section{References}

${ }^{1}$ C. J. Smithells: Metals Reference Book. Interscience Publishers Inc. New York (1949), p. 469.

${ }^{2}$ W. E. Parkins, G. J. Dienes, and F. W. Brown: Pulse-Annealing for the Study of Relaxation Processes in Solids. Jnl. Applied Physics (Aug. 1951) 22, No. 8, pp. 1012-1019.

${ }^{3}$ G. W. Wensch, K. B. Bruckart, and M. Conolly: Electropolishing of Tantalum. Metals Progress (March 1952) 61, p. 81.

G. W. WENSCH is Research Metallurgist, K. B. BRUCKART is Metallurgist, and R. H. DEIBLER is Physicist for Fansteel Metallurgical Corp., North Chicago, III. 